\title{
Multimodal composition and assessment: a sociocultural perspective
}

\section{Kenneth Silseth \& Øystein Gilje}

To cite this article: Kenneth Silseth \& Øystein Gilje (2017): Multimodal composition and assessment: a sociocultural perspective, Assessment in Education: Principles, Policy \& Practice, DOI: 10.1080/0969594X.2017.1297292

To link to this article: https://doi.org/10.1080/0969594X.2017.1297292

曲 Published online: 05 Mar 2017.

Submit your article to this journal 준

Џll Article views: 255

Q View related articles $\sqsubset$

View Crossmark data $[\pi$

7 Citing articles: 1 View citing articles 


\title{
Multimodal composition and assessment: a sociocultural perspective
}

\author{
Kenneth Silseth ${ }^{a}$ and $\varnothing y s t e i n ~ G i l j e^{b}$ \\ a'Department of Education, University of Oslo, Oslo, Norway; bepartment of Education and School Research, \\ University of Oslo, Oslo, Norway
}

\begin{abstract}
In this article, we examine how assessment is enacted and negotiated in a school project that involves multimodal composition. The case is a project on advertisement in which lower secondary students collaboratively composed multimodal commercials about various products and topics. The theoretical framework is based on sociocultural perspectives on learning and assessment, and video data of classroom interaction are subjected to detailed analysis. The findings document the consequences of decoupling production and assessment practices. The analysis show that written texts and multimodal texts have different statuses in the project because of how they are assessed and that this has consequences for students' participation as learners. In addition, the analysis shows how students position themselves differently towards resources that are intended to help them in summative assessment situations. We discuss issues that teachers may reflect upon when planning and executing multimodal composition in schools.
\end{abstract}

\section{ARTICLE HISTORY}

Received 30 October 2015

Accepted 15 February 2017

\section{KEYWORDS}

Formative assessment; summative assessment; multimodal composition; interaction analysis; sociocultural theory

\section{Introduction}

In recent decades, scholars have stressed the need to develop assessment practices that not only measure what students have learned but also enhance learning (Black \& Wiliam, 1998, 2009; Gipps, 1999; Sadler, 1998). This change has led scholars to challenge existing assessment practices, in which summative assessment has often been the primary activity, and emphasise formative assessment. However, because of the increasing use of new technology in classroom practices around the world, we need more knowledge about the complex relationship between formative and summative assessment in school projects that involve multimodal composition (Black, 2015; Cope \& Kalantzis, 2013). This type of knowledge will provide policy-makers, administrators, educators and researchers with insights into how to deal with the assessment of writing processes and products when multimodal composition is enacted in school practices.

In this article, we examine how assessment is enacted and negotiated in a school project that involves multimodal composition, in which lower secondary students collaboratively 
composed commercials (short films) about various products and topics in the subject of Norwegian (L1). Recently, research that empirically addresses assessment practices related to multimodal composition in educational settings has begun to emerge (Aagaard \& Lund, 2013; Godhe, 2013; Jewitt, 2003; Towndrow, Nelson, \& Yusuf, 2013). However, there is a need to gain more knowledge about how assessment is actually talked about when students engage in multimodal composition. We are particularly interested in examining how teachers and students negotiate assessment practices in classroom interactions. This type of analysis enables us to grasp how the various dimensions of formative and summative assessments are actually realised and enacted in classroom practices that involve multimodal composition.

The analysis is grounded in a sociocultural perspective on learning and assessment (Elwood \& Murphy, 2015; Gipps, 1999; Lund, 2008; Moss, Pullin, Gee, Haertel, \& Young, 2008 ), and video data of classroom interaction that occurred during the project are subjected to detailed analysis. From a sociocultural perspective, assessment should be closely coupled with learning and enacted as dynamic and meaningful in relation to how students come to see themselves as learners. In this article, the aim is to answer the following two interlinked research questions:

- How is assessment enacted in a school project on multimodal composition?

- How do assessment practices influence students' participation as learners?

\section{Assessment and multimodal composition}

Much research has been devoted to the assessment of texts based on the mode of writing. Scholars have examined both how the assessment of students' written texts is carried out in classrooms and how the assessment of students' writings should be enacted to support learning. Research within this tradition has demonstrated the value of proper feedback and guidance during the writing process, and formative assessment has proven to be of great importance when supporting learners. Research shows that students who are provided precise and just-in-time support during the writing process often perform better than students who do not receive support and scaffolding (Black \& Wiliam, 1998; Bransford, 2000; Parr \& Timperley, 2010; Wardle \& Roozen, 2012).

A growing number of countries provide students with the opportunity to work with multimodal texts, that is, texts that consist of various modes (e.g. moving images, images, written text and symbols), such as film, web production, digital stories and animation (Erstad, 2008; Gilje, 2010, 2015). Because of this, there has been an increasing interest in how to develop supportive assessment practices in school projects that involve the production of multimodal texts (Kalantzis, Cope, \& Harvey, 2003). During the last decade, quite a few empirical studies that address how assessment is enacted in the context of multimodal composition have emerged (Aagaard \& Lund, 2013; Adsanatham, 2012; Boston, Cohn, McKittrick, \& Snead, 2014; Godhe, 2013; Jewitt, 2003; Silseth, 2013; Towndrow et al., 2013; Vincent, 2006). In a well-cited study in this field, Jewitt (2003) examines the use of multimodal resources in a science classroom and finds that 'diagrams, drawings, and three-dimensional models are all brought into the learning of science, and at the same time, as far as the teacher is concerned, these stand apart from the process of assessment' (p. 98). Thus, the findings suggest that even though the teacher provided the students with opportunities to engage with multimodal learning resources, these resources were not included in the 
process of assessing students' learning trajectories. A decoupling of production practices and assessment practices was identified.

According to Aagaard and Lund (2013), teachers appear to lack experience with and research-based knowledge about how to assess multimodal texts. In their study of teachers' practices in assessing multimodal texts, they conclude that teachers adopted various strategies when dealing with assessment and new technologies. However, many of the teachers saw learning as 'acquiring factual content that should be tested on an individual basis, isolated from social or material assistance' (p. 236). This means that many teachers will not be oriented towards the possibility of assessing texts made by students using technological cultural resources, especially when such activities involve student collaboration.

Godhe (2013) studied how assessment criteria were being used in a school project in which students made argumentative multimodal texts, such as digital stories and short movies. The findings show that neither the students nor their teacher were attuned to the assessment criteria when producing the texts. Instead, they were mainly preoccupied with solving the task of composing the text, without orienting themselves towards the criteria that were supposed to be used in assessing the final stories. Thus, Godhe also identifies a decoupling of assessment practices and production practices. This study shows that the criteria were only constituted as a framework describing what to include in the task or assignment. In other words, it enabled the students to structure their work, but what the assessment criteria really meant - and how they could be interpreted and made meaningful in relation to the various multimodal texts that the students composed - was not addressed in the instructional design.

In a recent study of digital storytelling based on a multimodal textual analysis, Towndrow and colleagues (2013) analysed how a teacher assessed the multimodal work of students in a 10-week unit. In order to make the assessment criteria transparent to the students, the teacher downloaded often-used assessment guidelines from the Internet and distributed them to the students as part of the digital storytelling project. The researchers conclude that a prescribed rubric can be helpful for students working on multimodal projects. However, they are sceptical about whether these types of de-contextualised assessment guidelines enable teachers to truly acknowledge and appreciate students' inventiveness and creativity. They stress that we must develop more dynamic tools for such purposes.

Another relevant issue here is the relationship between assessment and how students are defined and constructed as learners. In the context of science education, Cowie (2005) has argued that in the assessment process, power relationships between teacher and student have a large influence on how students see themselves as learners. She emphasises that 'assessment can be seen to shape how students come to know, do and affiliate with science in both the short term and long term as part of seeking meaning within and through classroom interactions' (p. 209). Thus, the findings of this study show that assessment practices shape what students see as valuable to learn and that through these assessment practices, students recognise specific way of participating as more valid than others. This issue is just as relevant in school practices in which multimodal texts are the objects of assessment, but little empirical research addresses these issues.

In sum, the existing body of research points to important issues and challenges that a teacher might face regarding assessment when introducing and carrying out assignments that involve multimodal composition. The review of the literature shows that even if students are provided with multimodal learning resources, this does not necessarily lead to a 
situation in which such resources are included in assessment practices. A prescribed rubric will not necessarily enable the teacher to recognise the richness of students' multimodal expressions, and many teachers will not assess multimodal texts when they are a part of student collaboration.

However, we also need more knowledge about how formative and summative assessments should be handled in projects that involves multimodal composition. We require more knowledge about how assessment practices and multimodal text production are managed when they are part of collaborative activities in classrooms (Elwood \& Murphy, 2015; Lund, 2008). This type of knowledge will allow us to discuss what issues future learning and assessment designs should address. As we will detail below, a sociocultural perspective on learning and assessment is well-suited to developing knowledge about these issues.

\section{A sociocultural perspective on learning and assessment}

Formative assessment has been described as 'the process of appraising, judging, or evaluating students' work or performance, and using this to shape and improve their competence' (Gipps, 2002, p. 78). It is about guiding students in their learning trajectories, linking learning and assessment in ways that are meaningful for the learners themselves. This form of assessment has also been studied within the context of feedback (Gamlem \& Smith, 2013; Hattie \& Timperley, 2007). From this perspective, when engaged in formative assessment practices, the teacher helps students see how their actions as learners contribute to the development of their learning trajectories, and, if necessary, he or she reconfigures these trajectories in ways that are understandable and meaningful for the learner and the subject under consideration. However, as Elwood (2006) has pointed out, many proponents of formative assessment retain an individualistic view of learning and assessment and are preoccupied with 'measuring something that is the property of the student' (p. 230).

From a sociocultural perspective, learning is seen as being mediated by cultural tools and analysed as situated in a specific practice, and it is often described as something that should be facilitated as problem-based and authentic (Greeno, Collins, \& Resnick, 1996; Hmelo-Silver, 2004; Lave \& Wenger, 1991). The act of assessment has been described as a particular type of goal-directed mediated action (Habib \& Wittek, 2007; Lund, 2008; Poehner \& Lantolf, 2005), which means that assessment must be analysed in relation to the social contexts in which it is enacted and the cultural resources available.

In order to analyse learning and assessment in classroom practices, as mediated by cultural tools, it becomes important to examine what kinds of cultural resources are made available when engaging in specific activities and how these resources are oriented to and used/rejected by the students when dealing with specific tasks (Newman, Griffin, \& Cole, 1989). How students interpret and understand tasks and assignments will also influence how they orient themselves to the activities in which they are engaged (Rajala \& Sannino, 2015; Rasmussen, Krange, \& Ludvigsen, 2003).

Moreover, according to a sociocultural perspective on assessment, choosing to only assess learners individually is problematic because learning and knowing are seen as socially constructed and embedded in social practices. Thus, socioculturally oriented scholars have also addressed the tension between individual and collective assessment practices (Lund, 2008; Roth, 1998; Sainsbury \& Walker, 2008). According to Lund (2008), 'What is assessed in this perspective would involve learners' capacity for sharing and constructing knowledge 
through joint efforts and by using available artefacts' (p. 34). If learning and knowledge creation are a social, collective and interactional accomplishment, teachers must find ways of tapping into these processes. The collective process of creating knowledge objects must be included in assessment practices, and students should be guided in how to contribute to a wider community of learners.

From a sociocultural perspective, assessments are viewed as interactive and dynamic and are described as 'activities in which students participate, just as they do in all of the other activities of a classroom system' (Greeno \& Gresalfi, 2008, p. 185). Assessment is seen as an ongoing activity in which the meaning and function of the activity are negotiated by teachers and students in and across changing contexts and situations. According to Elwood and Murphy (2015), it is crucial to focus on how learning emerges in discourses if we want to understand how assessment can be connected to knowledge, teaching and contexts that can facilitate learning. This implies that assessment practices have implications for how students are defined and constructed as learners (Cowie, 2005; Moss et al., 2008; Pryor \& Crossouard, 2008). Assessing students' contributions has a more profound impact on students' learning trajectories than simply measuring the level of cognitive skills being performed; it contributes to developing frames in which students see themselves as learners and knowers (Silseth \& Arnseth, 2011). We argue that the ways in which students are assessed have implications for how students are positioned in classroom practice.

Thus, in order to understand the complex relationship between formative and summative assessment in school projects that involve multimodal composition, we must more closely examine how assessment is enacted in situ. Thus, it is important to analyse how assessment is enacted in naturally occurring student-teacher interactions (Shepard, 2000). We must analyse how students orient themselves to the established assessment practices and the various cultural resources available for participation, and we must analyse how teachers and students negotiate what issues to consider when assessing student participation in multimodal composition.

\section{Research context, method and analytical procedures}

\section{Research context}

The data subjected to analysis are derived from a larger qualitative study in Norway called Knowledge in Motion Across Context of Learning, in which we followed a group of students during the lower secondary years (ages 13-16). In this study, we examined students' participation in lessons in various core subjects, and when the students attended ninth grade, they participated in a school project about advertisements in the subject of Norwegian (L1). The curriculum reform named Knowledge Promotion (2006, revised 2013) consists of so-called competence aims in each subject, which should guide educators creating specific assignments for students regarding their instructional practices. In the subject of Norwegian, one competence aim states that students should be able to 'describe the interplay between aesthetic devices in multimodal texts, and reflect upon how we are influenced by sound, language, and images.' Learning about different genres and how various types of communicative modes influence people is an important part of the national curriculum in this subject. In the advertisement project, we followed two classes with a total of 52 students over several days, videotaping classroom interactions in eight lessons. 


\section{Method and analytical procedures}

We collected various types of data from the project: video data of classroom interactions, field notes from each session, pictures taken by researchers of classroom activities, documents that are circulated in practice and student products. In Table 1, the various data materials are displayed, together with descriptions of what roles they have in the study.

In the study, the primary data are video data of social interactions. The other types of data function as background information, which is used to inform the analysis of the video data. This means that the other types of data are secondary and used whenever they are relevant in understanding what appears in the video data. The advantage of video data is that we can examine actual sequences of talk and action in detail in the settings in which the studied activities are being carried out (Erickson, 2007; Goodwin, 1994). As shown within various branches of the sociocultural tradition, critical issues regarding how students and teachers orient to and interpret activities can be examined by analysing how learning and meaning-making unfold moment-by-moment during social interaction (Engle, 2006; Ludvigsen, 2012; Silseth \& Arnseth, 2016). We argue that an analysis of how assessment is enacted interactionally moment-by-moment will enable us to examine how multimodal composition practices are shaped by how the participants are oriented towards and dealing with assessment.

When video recording lessons, one researcher was present all the time, and he alternated between filming plenary activities and following specific groups. When deciding what groups to follow in the project, we had to consider our need to collect high-quality data. Because we based our analysis on talk and social interaction, we needed students who were inclined to speak and comfortable with working in groups during the project. Because we relied on video data illustrating interactions during a project that was time-limited, it was necessary to follow groups that would not 'break down' during the project.

In order to organise and analyse the video data, we employed thematic coding (Braun \& Clarke, 2006), using the software programme NVivo. A theme says something interesting and important about the data that is relevant to the research question and represents a type of pattern within the total data corpus. This technique enabled us to select interactional episodes that were particularly relevant in addressing the research question, episodes in which issues and tensions regarding assessment were handled and negotiated by the teacher and students during the advertisement project. After categorising the data into various thematic chunks, we carefully selected episodes of interactions that illustrate important identified

Table 1. Data sources and their use in the study.

\begin{tabular}{|c|c|}
\hline Data source & Use in the study \\
\hline Video data of social interactions & $\begin{array}{l}\text { Enable a detailed analysis of how teachers and students negoti- } \\
\text { ated assessment during the project in situ. }\end{array}$ \\
\hline Field notes & $\begin{array}{l}\text { Enable us to keep track on the unfolding of the project and } \\
\text { provide information about the context of the study. }\end{array}$ \\
\hline Pictures taken by researchers of classroom activities & $\begin{array}{l}\text { Enable us to zoom in on and visualise activities that were not } \\
\text { captured on video. }\end{array}$ \\
\hline Documents & $\begin{array}{l}\text { Enable us to provide a description of various factors that con- } \\
\text { tributed to structuring the activities and the project. The doc- } \\
\text { ument called 'the project sheet' was particularly important. }\end{array}$ \\
\hline Student products & $\begin{array}{l}\text { Enable us to understand what artefacts students produced dur- } \\
\text { ing the project. The commercials and the written assignments } \\
\text { were particularly important. }\end{array}$ \\
\hline
\end{tabular}


issues regarding assessment in the project. We regard these as recurring issues in the project. The reason for presenting and analysing these specific social interaction vignettes is because they demonstrate specific aspects of the assessment practice that was developed and how this influenced students' participation as learners. One important analytical strategy involves analysing how the participants responded to one another's utterances, turn-by-turn, in the selected episodes and co-constructed meaning and understanding (Heath, Hindmarsh, \& Luff, 2010; Jordan \& Henderson, 1995). The transcription conventions that we use are based on a modified version of Jefferson's (2004) classical system (see Appendix).

\section{Results}

In the advertisement project, the students produced two types of texts. The first was a multimodal text, a short commercial, which students produced collaboratively in groups. The groups could choose what the commercial should be about, and they produced commercials about hairspray, milk, an anti-bullying website, MacDonald's, Coca-Cola, a computer game and recycling. In addition to producing content about topics they themselves found interesting, many of the students travelled outside school and visited other places in their local community. Here, they gathered information and used their mobile phones to create footage for their commercials. The students were guided and supported by the teachers during their multimodal composition, but they did not receive grades on this activity or product. The teachers told the students that the reason for not grading the multimodal text was because they found it difficult to assess group work because the teachers do not know who has contributed and who has not. The second text that the students made was a written text, which they composed individually. The text was produced at school after they made the commercials, and students were supposed to reflect upon the process of making the multimodal text, the interplay between the various modes and how people might be influenced by commercials. The students received grades on this text.

On the first day of the project, the teacher initiated the work by reviewing what students knew about the conceptual aspects of advertisement based on homework and reading assignments about this topic in the textbook, conducted as a preparation for the project. The students had been introduced to perspectives on analysing commercials, such as the AIDA principle, which is described in the textbook. AIDA stands for attention, interest, desire and action, which are the four dimensions that should be considered when analysing or making commercials. Then, the project sheet was distributed to the students, in which the assignments were described, and the teacher explained the content of the sheet in detail. The teacher explained to the students that the process of making the commercial would help them during the second assignment, and they were encouraged to write down their reflections on making the commercial during the production process. Before the students began working on the multimodal text, the teacher described how similar projects had been carried out by students before and showed a commercial that former students made about the soft drink Coca-Cola.

In the following, we will analyse three key episodes that together document important tensions regarding how and what students and teachers considered important about both the production and assessment practices. The analysis of Episode 1 demonstrates how the status of the multimodal text was established interactionally. The analysis of Episode 2 shows how the practice of not performing a summative assessment of the multimodal text 
had implications regarding student participation. The analysis of Episode 3 exemplifies how students position themselves differently towards resources made available in the assessment practice. Analysing these episodes demonstrates important issues to consider when realising school projects that include multimodal composition and collaborative activities. Because the three episodes occurred in lessons in the subject of Norwegian, the extracts have been translated into English.

\section{Establishing the status of the multimodal text}

When reviewing the student-teacher interactions that unfold during the project, we found that the teachers often stressed how students should reflect upon conceptual matters when creating their commercials. More specifically, the teachers often displayed discontent regarding what they saw as a lack of orientation among the students towards reflection and critical awareness during the production practice. In the following episode of interaction, the teacher tries to attune the students to conceptual matters. The issue of assessment becomes relevant, and the statuses the various types of texts have in the project become evident. The teacher encounters one of the student groups and inquires about what they have done so far. The group is making a commercial about garbage bags and has employed several humorous devices. In the commercial, they had recorded various scenes in which a particular type of large garbage bag is used for purposes other than what it was originally designed for. One episode concerns how one can use a garbage bag to transport a dead body; it becomes a body bag, a reference to crime series from popular culture. The student explains to the teacher what the commercial is about and what they plan to do. Then, as seen in Figure 1, the teacher tries to orient the students towards the more curricular, conceptual aspects of the project work (Kontekst is the name of the textbook that the students use).

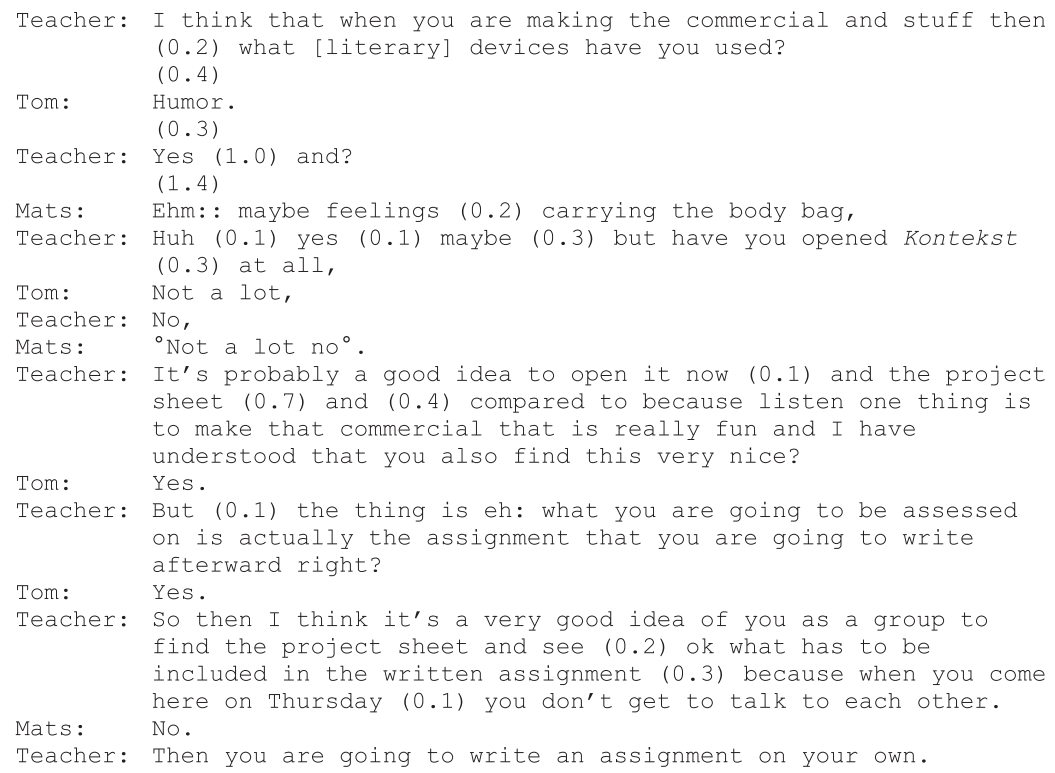

Figure 1. Establishing the status of the multimodal text. 
At the beginning of the episode, the teacher attempts to orient the students towards the concept of a 'device,' which is an important subject-specific concept in the project (lines $1-2)$. It is described in the project sheet as something they must relate to, and they are asked to reflect upon how they have used various literary devices in the commercial when carrying out the written assignment. However, not only does the teacher make the students aware of these devices, she also makes them reflect on what types of devices they have used. In his response, Tom suggests that the group has used 'humour' as a device (line 4). The teacher acknowledges this, but she wants the group to expand their account (line 6). After a lengthier pause, Mats suggests that 'feelings' are a device and refers to a specific part in the commercial in which this is relevant (line 8). However, the teacher does not seem to be satisfied with this answer, orients the students to the textbook and asks whether the students have used it during their work on the commercial (lines 9-10). When the students make it clear that they have not used this learning resource, the teacher recommends that the students start to use it and the project sheet (lines 14-15). The teacher follows up with remarks about how the students are having fun when making the commercial, but makes it clear that this is not enough (lines 16-17). She acknowledges that the students find this activity fun and engaging, but then orients the students towards the product that will be assessed, the written assignment (lines 19-21). Tom acknowledges this (line 22), and the teacher then begins to instruct the students. Here, she addresses the distinction between group work and individual work and stresses that the learning situation they are now in is different from situations in which they produce something that will be assessed (lines 23-26 and line 28).

The analysis demonstrates how the teacher and students negotiate the meaning of the multimodal text and related conceptual aspects and how the status of this text is established and recognised by the participants. The teacher acknowledges the commercial that the student group has made, but makes the students aware that the commercial, which they find engaging and exiting to create, is only a stepping stone on their path to creating a knowledge object that will be assessed. We can also interpret this as a request or appeal that the students become more engaged in what is considered important and spend less effort on activities that seem to engage and motivate these students. As compared to the written report, the commercial has a different status in the project, something that the teachers constantly make the students aware of, which is a stance and perspective they also appropriate as learners.

\section{Implications of not performing a summative assessment of the multimodal text}

When reviewing the video data of the interactions that occurred during the project, many of the students seem to participate in ways that are influenced by the statuses of the two types of texts they will compose. Furthermore, the statuses of the texts seem to be related to how they are being assessed by the teachers. In the following episode, we zoom in on a group of five students who are engaged in making a commercial about Coca-Cola. They have decided to shoot various scenes in which the actors receive a boost from drinking Coke in various situations and are now discussing how to deal with this task. As mentioned earlier, the commercial that was shown to the class in the opening plenary session was about Coke. Then, as seen in Figure 2, one of the students begins to confront the rest of the group with the possibility of choosing another product or topic to make a commercial about. 


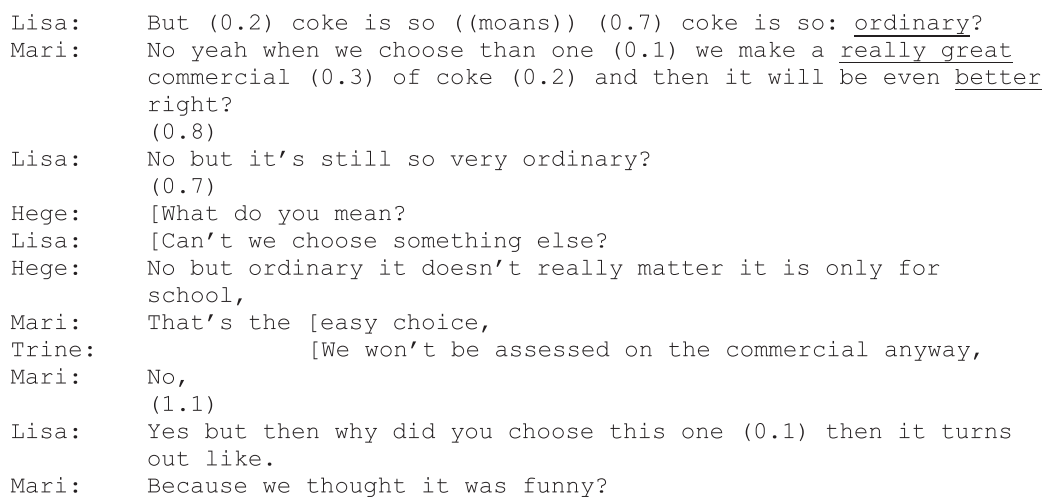

Figure 2. Implications of not performing a summative assessment of the multimodal text.

In the opening utterance, Lisa displays discontent with the group's choice to make a commercial about Coke (line 1). According to her, it is too common a topic to make a commercial about, and by moaning and emphasising the word 'ordinary', she begins the process of attempting to convince the other group members to choose a different topic for their commercial. In her response to Lisa, Mari states that they should continue to work on the Coke commercial, making a great one that will stand out (lines 2-4). After a lengthier pause, Lisa replies that what Mari proposes will not make a difference: 'it's still so very ordinary' (line 6). Lisa suggests that they change the product (line 9), but we can also see that Hege joins the conversation (lines 8 and 10-11). As a response to Lisa's suggestion to change the product, Hege orients the group towards the context of production, and by saying that 'it is only for school' (lines 10-11), she argues that because the commercial is being made as part of a school assignment, the question regarding what is ordinary is irrelevant. Mari follows up on this and states that making a commercial about this product is an easy way to complete the assignment (line 12). Then, Trine contributes to the conversation and supports Hege's account by reminding the group that the commercial will not be graded or assessed (line 13). When Mari supports Trine (line 14), a lengthier pause occurs before Lisa attempts to counter these arguments by orienting the group towards the importance of having a rationale for choosing the product they have decided to focus on in case the teacher requests one (lines 16-17). However, Mari counters this by stating that they only have to say it was fun (line 18), insinuating that they do not have to come up with a very sophisticated account. Ultimately, the group makes a commercial about Coke.

The analysis demonstrates the pitfalls of only assessing some types of products and tasks when students are involved in multimodal composition practices in school. Here, a potential consequence of creating a distinction regarding the statuses of the multimodal and written texts, as displayed in the analysis of Episode 1, is demonstrated. Lisa wanted to produce a multimodal text of high quality that would stand out. However, the other group members represent students who are not willing to invest time and effort due to the context of production and the types of assessment that are carried out. Lisa's argument for investing more time and effort into the work on the commercial is resisted by the rest of the group. The other group members seemed to be guided by the fact that the multimodal 
text will not be part of the summative assessment. They did not see a reason to invest too much time and effort when making the commercial because it would not be subjected to summative assessment, and they are only willing to produce 'good enough products' that the teacher will find acceptable.

\section{Student positioning towards resources in assessment practices}

The third issue we will highlight is how students interpret and make use of the resources available to them when participating in the advertisement project. As mentioned earlier, the students were encouraged to write down reflections when making the commercials, which should function as resources when producing the written text that will be subject to summative assessment. However, the data suggest that students positioned themselves differently in regard to this practice. In the next episode, displayed in Figure 3, we zoom in on another student group that is collaboratively reflecting on how the above-mentioned AIDA principles relate to the commercial they have made. One of the students, here called Lise, leads this conversation, and she displays discontent regarding the other group members' lack of attunement to this topic of conversation. During the episode, the teacher joins the group, which prompts the group to comment on issues regarding preparation for the written

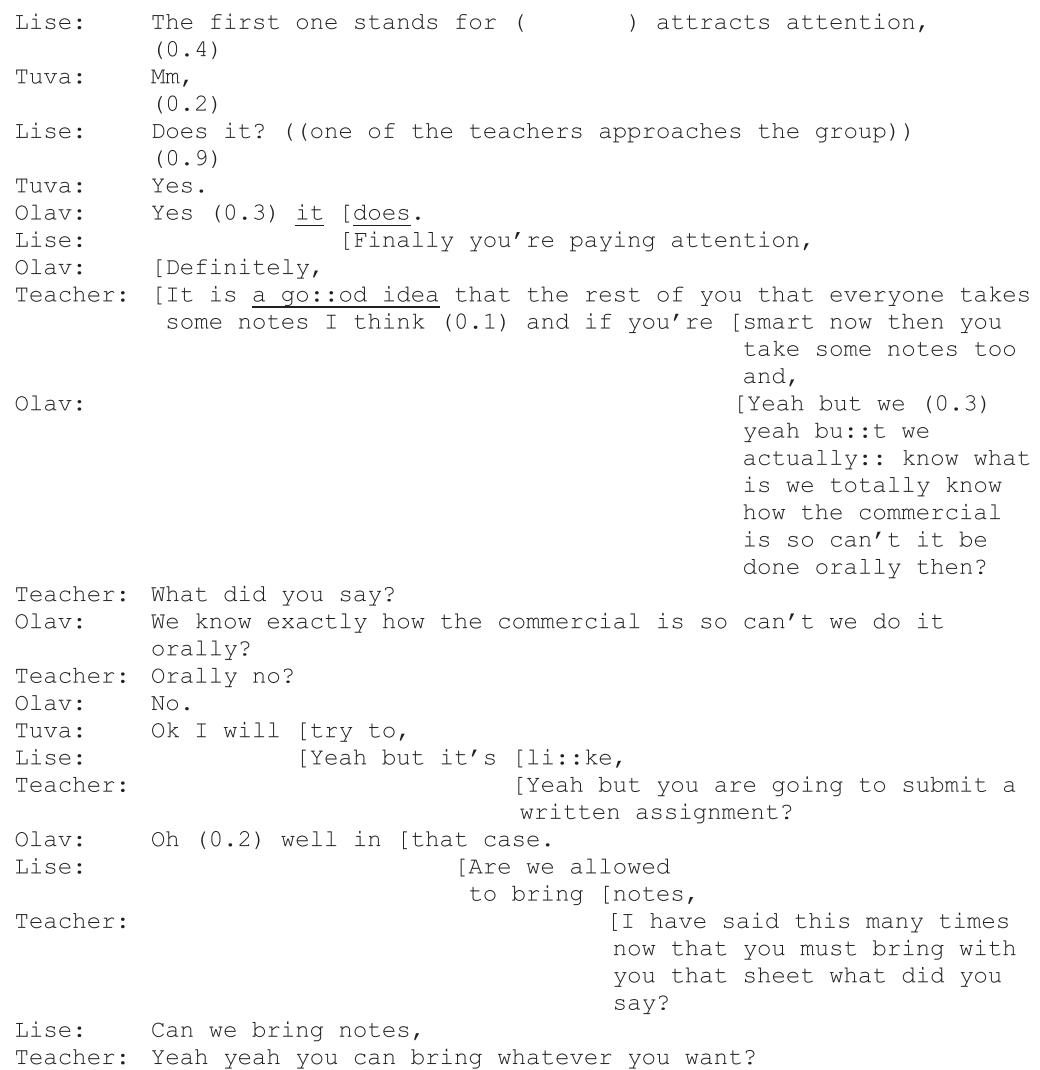

Figure 3. Student positioning towards resources in assessment practices. 
assignment. Thus, they enter the phase in which they reflect upon their multimodal text by means of conceptual matters. In the end, these concepts will materialise in the written text and be subjected to summative assessment.

In the opening utterance, Lise addresses the first letter in AIDA, which stands for 'attention, and orients the rest of the group towards the importance of attracting attention when making commercials (line 1). After a pause, Tuva responds using the continuer 'mm.' This makes Lise request an opinion from the rest of the group about whether their commercial attracts attention or not (line 5). When this happens, the teacher approaches the group. The other group members then respond to her request (lines 7-8); however, they do so without elaborating on how it attracts attention. Lise begins to joke about how they change participation patterns due to the presence of the teacher (line 9). However, the teacher orients the group towards an activity that will be beneficial in the future, namely writing down notes (line 11-14). The teacher does not mention what these notes should contain. When Olav responds to the teacher's utterance, he overlaps with her, indicating that he is very eager to voice his opinion. Here, he argues that because the group knows what the commercial is about, they can deal with this task orally, instead of writing down the issues they talk about (lines 15-21). The teacher rejects this suggestion (line 25), and she then orients the students to the written assignment. Olav's response to the teacher's rejection ('Oh (0.2) well in that case') can be interpreted as indicating that he is not attuned to the possible function of notes in the future (line 31). In addition, he does not receive support in making this connection. Instead, the teacher says that she has mentioned the sheet that they can use on the test many times before (lines 34-37). In the end, Lise realises the function of the notes and asks if they can bring the notes with them, something that the teacher responds positively to (line 38-39).

The analysis demonstrates how students can position themselves differently towards resources that are available in the assessment practice and how a teacher manages this interactionally. When the teacher encourages the students to create written resources when discussing their commercial, it becomes clear that not all students recognise the function of such resources. One of the students goes against this suggestion and argues that they do not need to engage in the practice of writing. One potential explanation could be that he does not find it relevant and he is not oriented towards the function of this resource in the future. The teacher then attempts to orient the students towards the assignment, commenting that they must produce a written assignment at the end of the project, without explaining how they can use the notes as a resource later. Thus, the episode demonstrates that some students lack knowledge about how to use this type of resource in a summative assessment situation and that teachers must support students in developing strategies for using such resources across assessment situations.

\section{Discussion and concluding remarks}

In this article, we have addressed two interlinked research questions: 'How is assessment enacted in a school project on multimodal composition?' and 'How do assessment practices influence students' participation as learners?' The motivation for asking these questions is an identified need to gain more knowledge about how assessment is negotiated in classroom interactions when students are given the opportunity to use various modes for expressing themselves. 
The findings document tensions between what the students consider to be important regarding assessment and what the teachers take into account in their assessment practices. In the advertisement project, the teachers formatively assessed the students during the production of the multimodal text through guidance. The students were given feedback on their work several times during the project and guided by the teachers towards the finalisation of their multimodal commercial. However, even though the students presented the final multimodal text in plenum to their peers, the teachers did not perform a summative assessment of this part of the assignment. A summative assessment was only provided for the individually produced written text. Our findings show that this way of organising learning and assessment practices influenced students' learning trajectories. The production practice in the project was, to some degree, designed coherently because the work on the written text was supposed to build on the multimodal text. However, because the assessment practice was not coherently designed, the students seemed to be more attuned to the work on written texts. If learning and knowing are collaborative and interactional achievements, then collective classroom activities should be included in both formative and summative assessment processes (Lund, 2008; Roth, 1998; Sainsbury \& Walker, 2008). This was not the case in the project reported on here, which influenced the ways in which the students participated.

Our study shows the potential consequences of a decoupling of production and assessment practices, as identified by Jewitt (2003). The findings show that students, when dealing with assignments that involve multimodal composition, can be sceptical about investing time and effort in producing these types of texts if they are not integrated thoroughly into the assessment practice. The choice to not perform a summative assessment of the multimodal text resulted in a situation in which several of the students were reluctant to invest time and effort in creating this type of text. Studies have found that summative assessment can foster learning if the information gained from these types of assessment is used formatively (Black, Harrison, Hodgen, Marshall, \& Serret, 2011). The findings in the present study show that creative students who wanted to be inventive and innovative were corrected by other students because they were attuned to the context of production and the fact that the commercials would not be given a grade.

Aagaard and Lund (2013) have argued that many teachers often see learning as acquiring factual knowledge that can be tested individually without material assistance. Our data show that students were allowed to use material resources in the assessment situation. However, the findings show that even if the students were allowed to produce resources during the production process that could help them in the summative assessment situation, students positioned themselves differently towards such resources. Students also need to be attuned to the possibility of using resources that are relevant to assessment across contexts and to be guided in using such resources competently in summative assessment situations. Studies within the sociocultural tradition have shown how students are positioned as learners in relation to assessment practices and how this shapes their learning trajectories (Cowie, 2005; Moss et al., 2008; Pryor \& Crossouard, 2008). We extend the existing knowledge by showing how students can position themselves towards established assessment practices. Our study points to the importance of finding new ways of involving students in the process of designing assessment practices for multimodal composition in school.

Our data show that the students were highly attuned to the future act of summative assessment and what kind of products would be subjected to such assessments. In her 
study, Godhe (2013) showed that assessment criteria only became relevant to the project when the multimodal texts were finalised. The criteria became tools for the students to use, guiding them in the process of deciding what to include in the texts, but what the criteria represented was not subject to discussion or negotiation. According to Towndrow and colleagues (2013), a prescribed rubric is not a very helpful tool for grasping and appreciating students' inventiveness and creativity. In the current study, the written assignment that would be assessed was often referred to during the process of creating the commercials, both by the students and the teachers. Nevertheless, there was also little discussion about the objectives that should be addressed in the individual writings. This is perhaps too much to ask of the students and must to be facilitated by a teacher who can support students in reflecting on how the assessment criteria can be used as resources when working on their multimodal texts.

This discussion points to three issues that teachers can reflect on when planning and executing similar projects that include work on both written and multimodal texts and individual and group work. (1) Teachers may consider developing assessment practices in which both written texts (such as essays and research papers) and multimodal texts (such as movies and digital stories) are subject to both formative and summative assessments. If not, they may risk a situation in which their students invest more time and effort in certain assignments within a project. For example, in addition to formatively assessing and guiding students' text productions, teachers can require students to make portfolios that include all the types of texts, which will constitute the foundation for summative assessment. (2) Teachers may consider developing assessment practices in which both formative and summative assessments are made relevant in the context of both individual and group work. If not, students may only prioritise the work format that is to be subjected to summative assessment. For example, in order to perform summative assessment of multimodal texts made in groups, teachers can require students to write reflection notes in which all members of the group reflect on the group process; the teacher can then evaluate this in relation to the other types of texts produced in a project. (3) Teachers can consider how to systemically support and guide students in developing knowledge about how to use the resources made available during the production process in summative assessment situations. For example, teachers can, at various stages during the production process, facilitate discussion of and reflection on what kind of resources are made available, such as notes from students' discussions, and how these can be used at later stages in the project.

Finally, assessment in learning environments, which includes new genres and multimodal texts, is a delicate matter. Research has shown that it is often difficult to alter established assessment practices (Prøitz, 2013). Even though many scholars have pointed out the need to develop effective tools for assessing new types of texts in schools, there is also a need for more knowledge about how assessments are enacted in naturally occurring classroom interactions. This is important because it can shed light on the function of assessment in the everyday lives of students and teachers. This study contributes to expanding the existing body of knowledge about assessment and multimodal composition in school and raises some issues that should be considered when designing future learning environments that involves collaborative activities and multimodal learning resources. 


\section{Acknowledgements}

We would like to thank all the teachers and students who have been part of this project, and given us the opportunity to learn about assessment practices in school. Your hospitality and openness have been valuable to an international research community, and to the field of teacher education. This work is funded by the Norwegian National Research Council, program FINNUT.

\section{Disclosure statement}

No potential conflict of interest was reported by the authors.

\section{Notes on contributors}

Kenneth Silseth is an associate professor at the Department of Education, University College of Southeast Norway. Among his research interests are student's identity work and learning trajectories in and across settings, and the use of different types of technologies in these processes. Silseth has published journal articles on topics such as game-based learning, simulations, social media and digital storytelling.

Øystein Gilje is an associate professor who works at Department of Teacher Education and School Research, University of Oslo, Norway. For more than a decade, Gilje has explored and published research on how young people construe meaning in their digital composing of multimodal texts in classrooms.

\section{References}

Aagaard, T., \& Lund, A. (2013). Mind the gap: Divergent objects of assessment in technology-rich learning environments. Nordic Journal of Digital Literacy, 8, 225-243.

Adsanatham, C. (2012). Integrating assessment and instruction: Using student-generated grading criteria to evaluate multimodal digital projects. Computers and Composition, 29, 152-174.

Black, P. (2015). Formative assessment: An optimistic but incomplete vision. Assessment in Education: Principles, Policy \& Practice, 22, 161-177.

Black, P., Harrison, C., Hodgen, J., Marshall, B., \& Serret, N. (2011). Can teachers' summative assessments produce dependable results and also enhance classroom learning? Assessment in Education: Principles, Policy \& Practice, 18, 451-469.

Black, P., \& Wiliam, D. (1998). Assessment and classroom learning. Assessment in Education: Principles, Policy \& Practice, 5, 7-74.

Black, P., \& Wiliam, D. (2009). Developing the theory of formative assessment. Educational Assessment, Evaluation and Accountability, 21, 5-31.

Boston, S. M., Cohn, J., McKittrick, M., \& Snead, R. (2014). Current conversations on multimodal assignments and assessments: A collaborative review of four recent texts. Computers and Composition, 31, 67-78.

Bransford, J. (2000). How people learn: Brain, mind, experience, and school. Washington, DC: National Academy Press.

Braun, V., \& Clarke, V. (2006). Using thematic analysis in psychology. Qualitative Research in Psychology, 3, 77-101.

Cope, B., \& Kalantzis, M. (2013). Towards a new learning: The scholar social knowledge workspace, in theory and practice. E-Learning and Digital Media, 10, 332-356.

Cowie, B. (2005). Student commentary on classroom assessment in science: A sociocultural interpretation. International Journal of Science Education, 27, 199-214.

Elwood, J. (2006). Formative assessment: Possibilities, boundaries and limitations. Assessment in Education: Principles, Policy \& Practice, 13, 215-232. 
Elwood, J., \& Murphy, P. (2015). Assessment systems as cultural scripts: A sociocultural theoretical lens on assessment practice and products. Assessment in Education: Principles, Policy \& Practice, $22,182-192$.

Engle, R. (2006). Framing interactions to foster generative learning: A situative explanation of transfer in a community of learners classroom. Journal of the Learning Sciences, 15, 451-498.

Erstad, O. (2008). Changing assessment practices and the role of IT. In J. Voogt \& G. Knezek (Eds.), International handbook of information technology in primary and secondary education (pp. 181194). Dordrecht: Springer.

Erickson, F. (2007). Ways of seeing video: Toward a phenomenology of viewing minimally edited footage. In R. Goldman (Ed.), Video research in the learning sciences (pp. 145-155). Mahwah, NJ: Lawrence Erlbaum.

Gamlem, S. M., \& Smith, K. (2013). Student perceptions of classroom feedback. Assessment in Education: Principles, Policy \& Practice, 20, 150-169.

Gilje, Ø. (2010). Multimodal redesign in filmmaking practices: An inquiry of young filmmakers' deployment of semiotic tools in their filmmaking practice. Written Communication, 27, 494-522.

Gilje, Ø. (2015). Writing within and across modes in filmmaking. In A. Archer \& E. Breuer (Eds.), Multimodality in writing: The state of the art in theory, methodology and pedagogy (pp. 153-171). Leiden: Brill.

Gipps, C. (1999). Socio-cultural aspects of assessment. Review of Research in Education, 24, 355-392.

Gipps, C. (2002). Sociocultural perspectives on assessment. In G. Wells \& G. Claxton (Eds.), Learning for life in the 21st century: Sociocultural perspectives on the future of education (pp. 73-83). Oxford: Blackwell Publishers.

Godhe, A.-L. (2013). Negotiating assessment criteria for multimodal texts. International Journal of Assessment and Evaluation, 19, 31-43.

Goodwin, C. (1994). Professional vision. American Anthropologist, 96, 606-633.

Greeno, J., Collins, A., \& Resnick, L. (1996). Cognition and learning. In B. Berliner \& R. Calfee (Eds.), Handbook of educational psychology (pp. 15-46). New York, NY: Simon \& Shuster MacMillan.

Greeno, J., \& Gresalfi, M. (2008). Opportunities to learn in practice and identity. In P. A. Moss, D. C. Pullin, J. P. Gee, E. H. Haertel, \& L. J. Young (Eds.), Assessment, equity, and opportunity to learn (pp. 170-199). New York, NY: Cambridge University Press.

Habib, L., \& Wittek, L. (2007). The portfolio as artifact and actor. Mind, Culture, and Activity, 14, 266-282.

Hattie, J., \& Timperley, H. (2007). The power of feedback. Review of Educational Research, 77, 81-112.

Heath, C., Hindmarsh, J., \& Luff, P. (2010). Video in qualitative research: Analysing social interaction in everyday life. Los Angeles, CA: Sage.

Hmelo-Silver, C. E. (2004). Problem-based learning: What and how do students learn? Educational Psychology Review, 16, 235-266.

Jefferson, G. (2004). Glossary of transcript symbols with an introduction. In G. H. Lerner (Ed.), Conversation analysis: Studies from the first generation (Vol. 125, pp. 13-31). Amsterdam: John Benjamins.

Jewitt, C. (2003). Re-thinking assessment: Multimodality, literacy and computer-mediated learning. Assessment in Education: Principles, Policy \& Practice, 10, 83-102.

Jordan, B., \& Henderson, A. (1995). Interaction analysis: Foundations and practice. Journal of the Learning Sciences, 4, 39-103.

Kalantzis, M., Cope, B., \& Harvey, A. (2003). Assessing multiliteracies and the new basics. Assessment in Education: Principles, Policy \& Practice, 10, 15-26.

Lave, J., \& Wenger, E. (1991). Situated learning: Legitimate peripheral participation. Cambridge: Cambridge University Press.

Ludvigsen, S. (2012). Commentary. Instructional Science, 40, 849-855.

Lund, A. (2008). Assessment made visible: Individual and collective practices. Mind, Culture, and Activity, 15, 32-51.

Moss, P. A., Pullin, D. C., Gee, J. P., Haertel, E. H., \& Young, L. J. (2008). Assessment, equity, and opportunity to learn. New York, NY: Cambridge University Press. 
Newman, D., Griffin, P., \& Cole, M. (1989). The construction zone. Cambridge: Cambridge University Press.

Parr, J. M., \& Timperley, H. S. (2010). Feedback to writing, assessment for teaching and learning and student progress. Assessing Writing, 15, 68-85.

Poehner, M. E., \& Lantolf, J. P. (2005). Dynamic assessment in the language classroom. Language Teaching Research, 9, 233-265.

Prøitz, T. S. (2013). Variations in grading practice-subjects matter. Education Inquiry, 4, 555-575.

Pryor, J., \& Crossouard, B. (2008). A socio-cultural theorisation of formative assessment. Oxford Review of Education, 34(1), 1-20.

Rajala, A., \& Sannino, A. (2015). Students' deviations from a learning task: An activity-theoretical analysis. International Journal of Educational Research, 70, 31-46.

Rasmussen, I., Krange, I., \& Ludvigsen, S. R. (2003). The process of understanding the task: How is agency distributed between students, teachers and representations in technology-rich learning environments? International Journal of Educational Research, 39, 839-849.

Roth, W.-M. (1998). Situated cognition and assessment of competence in science. Evaluation and Program Planning, 21, 155-169.

Sadler, D. R. (1998). Formative assessment: Revisiting the territory. Assessment in Education: Principles, Policy \& Practice, 5, 77-84.

Sainsbury, E. J., \& Walker, R. A. (2008). Assessment as a vehicle for learning: Extending collaboration into testing. Assessment \& Evaluation in Higher Education, 33, 103-117.

Silseth, K. (2013). Surviving the impossible: Studying students' constructions of digital stories on World War II. Learning, Culture and Social Interaction, 2, 155-170.

Silseth, K., \& Arnseth, H. C. (2011). Learning and identity construction across sites: A dialogical approach to analysing the construction of learning selves. Culture \& Psychology, 17, 65-80.

Silseth, K., \& Arnseth, H. C. (2016). Frames for learning science: Analyzing learner positioning in a technology-enhanced science project. Learning, Media and Technology, 41, 396-415.

Shepard, L. A. (2000). The role of assessment in a learning culture. Educational Researcher, 29, 4-14.

Towndrow, P. A., Nelson, M. E., \& Yusuf, W. F. B. M. (2013). Squaring literacy assessment with multimodal design: An analytic case for semiotic awareness. Journal of Literacy Research, 45, $327-355$.

Vincent, J. (2006). Children writing: Multimodality and assessment in the writing classroom. Literacy, 40, 51-57.

Wardle, E., \& Roozen, K. (2012). Addressing the complexity of writing development: Toward an ecological model of assessment. Assessing Writing, 17, 106-119.

\section{Appendix: Transcription conventions}

\begin{tabular}{|c|c|}
\hline Sign & Explanation \\
\hline$(2.5)$ & Time interval between speech in tenths of a second. \\
\hline$<>$ & $\begin{array}{l}\text { Right and left carats indicate that the talk between the participants speeded } \\
\text { up or slowed down. }\end{array}$ \\
\hline word & Underlining indicates emphasis on words and expressions. \\
\hline[ & Brackets indicate where overlapping talk starts. \\
\hline$:::$ & Colons indicate the lengthening of a word or sound. \\
\hline.,$?$ & $\begin{array}{l}\text { Punctuation markers indicates intonation. The period indicates falling into- } \\
\text { nation. The comma and question mark indicate rising intonation. }\end{array}$ \\
\hline & Empty parentheses indicate that it was difficult to hear what was said. \\
\hline${ }^{\circ}$ word ${ }^{\circ}$ & Indicates that the word or sound is softer compared to the surrounding talk. \\
\hline & A sentence that appears within double parentheses describes an action. \\
\hline
\end{tabular}

